\title{
CRITERION FOR VERIFICATION OF THE GENERALIZED LAW OF HOOKE
}

\author{
Duishenaliev, T.; DuishembieV, A. \& MeKenbaev, B.
}

Annotation. To discuss the generalized Hooke's law, we propose a new criterion derived for axial extension and compression of solid cylinders without the influence of the hypothesis of uniaxiality of the stressed state. Integration of the equation of the axial motion is carried out, at which the generalized Hooke's law and boundary conditions on the basis and lateral surface of a cylindrical sample are used. The resulting equation connects the load with axial and annular deformations. This equation gives a new interpretation of the load-strain diagram and describes the results of the experiments throughout its entire length at the same values of the material constants.

Keywords: tensile-contraction, load, deformation, generalized Hooke's law
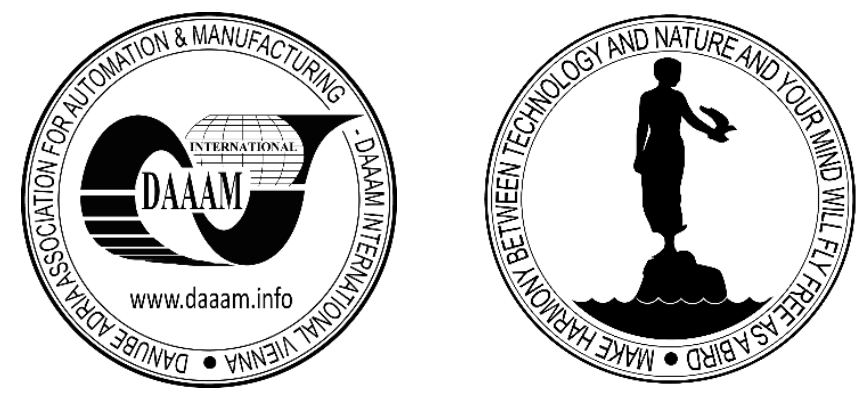

Data of the authors: Doctor of Physical and Mathematical Sciences, Professor Duishenaliev, $\mathrm{T}$ [uratbek]*; post-graduate student Duishembiev, A[lmaz]**; Candidate of Physical and Mathematical Sciences Mekenbaev B[aktybek]***; * National Research University MPEI, Krasnokazarmennaya 14, Moscow, Russia, **Kyrgyz State Technical University named after I.Razzakov, Ch.Aitmatov Ave. 66, Bishkek, Kyrgyzstan, ***International University of Innovative Technologies, Ankara street 1/17, Bishkek, Kyrgyzstan, duishenaliev@mail.ru, ads.t87@mail.ru, mekenbt@mail.ru

This Publication has to be referred as: Duishenaliev, T[uratbek]; Duishembiev, $\mathrm{A}$ [lmaz] \& Mekenbaev, B[aktybek] (2018). Criterion for Verification of the Generalized Law of Hooke, Chapter 16 in DAAAM International Scientific Book 2018, pp.175-184, B. Katalinic (Ed.), Published by DAAAM International, ISBN 978-3-902734-19-8, ISSN 1726-9687, Vienna, Austria

DOI: $10.2507 /$ daaam.scibook.2018.16 
Duishenaliev, T.; Duishembiev, A. \& Mekenbaev, B.: Criterion for Verification of t...

\section{Introduction}

Among the ratios of binding between the components of the stress tensor and deformation, the generalized Hooke's law takes place particularly. It was established in papers (Duishenaliev, T. 2017; Zhakypbekov, A. \& Duishenaliev, T 2004) that this law has the consistency inherent in the fundamental laws of nature. Only some of the strain components can be measured instrumentally, while the components of the same voltage can not be directly measured. An experienced way to verify this law is impossible. All these forces us to resort to indirect methods.

In the above papers (Duishenaliev, T. 2017; Zhakypbekov, A. \& Duishenaliev, $\mathrm{T} 2004$ ) the equations of the boundary value problem are compiled on the basis of the generalized Hooke's law for axisymmetric stressed states. The simplifications in which the usual criterion becomes the solution of such a problem are analyzed in detail.

The new criterion (Duishenaliev, T. 2017; Zhakypbekov, A. \& Duishenaliev, T 2004 ) is derived from the same equations of the boundary-value problem, but without the simplifications used in deriving the generally accepted criterion. Here, a differential equation was integrated expressing the condition of dynamic equilibrium of the cylinder in axisymmetric compression, axisymmetric stretching and axisymmetric compression with lateral hydrostatic pressure. The boundary conditions were adopted (were taken) without the hypothesis of uniaxiality of the stressed state.

The above approach to integrating the equation of dynamic equilibrium of a cylinder in axially symmetric stressed states led to a new equation for the experimental verification of the consistency of the generalized Hooke's law. This equation called the equation of the load-deformation diagram of Zhakypbekov, A. (Duishenaliev, T. 2017; Zhakypbekov, A. \& Duishenaliev, T 2004), contains only those quantities that are measured during the experiments, but nevertheless, it corresponds to the most general representation of the boundary conditions of the boundary value problem. It is shown (Zhakypbekov, A. \& Duishenaliev, T 2004) that the usual criterion is contained in the new as a special case.

Comparison of the new criterion with the results of experimental data of different scientists (Duishenaliev, T. 2017; Ilyushin, A. 1971; Rudskoy, A. \& Duishenaliev, T. 2016; Zhakypbekov, A. \& Duishenaliev, T 2004; Zhakypbekov, A. 1980; Zhukov, A. 1954) leads to a completely unexpected conclusion about the validity of the generalized Hooke's law. It turned out that this law describes very well the behavior of bodies not only at the beginning of the diagram, but also in the middle and final parts of it and called the areas of flow and hardening of materials. In this case, the mechanical constants do have the same values throughout the experimental diagram.

On the basis of compiled computer programs, the material constants are determined in the Matlab system, the theoretical and experimental values of deformations and stresses are compared, including their values on the octahedral plane (Duishenaliev, T. 2017; Zhakypbekov, A. \& Duishenaliev, T 2004). 
It is shown (Duishenaliev, T. 2017; Zhakypbekov, A. \& Duishenaliev, T 2004) that the generally accepted criterion is applicable only for one row of the experimental array, which corresponds to the onset of uniaxiality in the loading process (of course, if the load and strain measurements are made at the same time). For the remaining points this criterion loses its validity (Demidov, S. 1979; Ilyushin, A. 1971). In contrast, the new criterion is applicable for all rows of the experimental array.

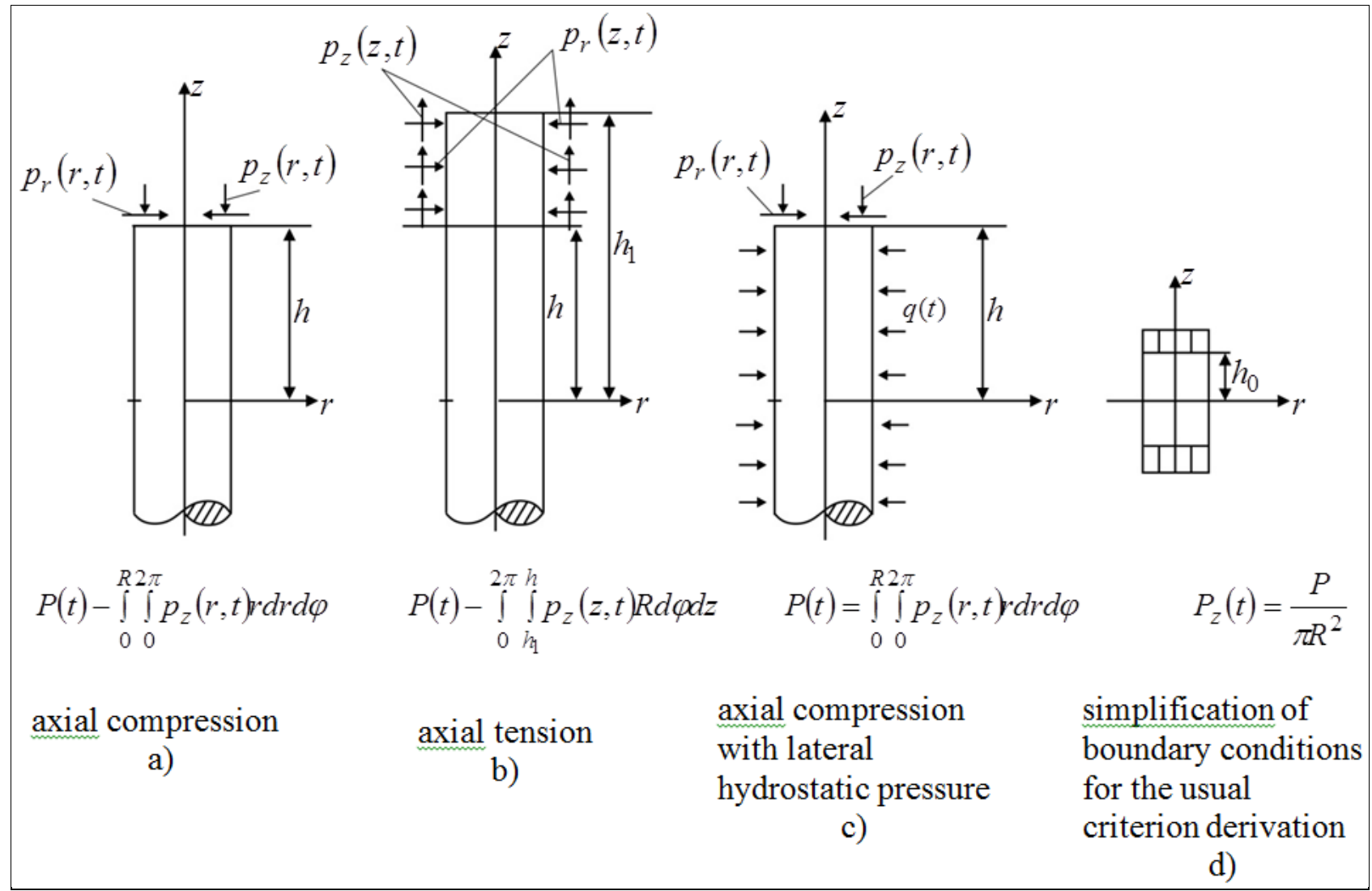

Fig. 1. The boundary conditions used in the derivation of a new and usual criteria

This state is predetermined by the following circumstances:

1. The generally accepted criterion is the solution of a static boundary-value problem with the boundary conditions shown in Fig. 1, d (Demidov, S. 1979, Greene, A. 1965; Mays, J. 1974; Novatsky, V. 1975). It is important to note that here we have in mind a solution that strictly corresponds to the formulation of the problem (no changes in time in the problem itself and its solution). In other words, this solution is valid only for that row of the experimental array, which corresponds to a uniform distribution of axial forces on the bases of the cylinder. On the experimental diagram, this line of the array corresponds to one of its points, which was named above the uniaxial point.

2. In contrast, in the new criterion, external forces in schemes a, b, c in Fig. 1 can have any, in addition, varying in time, distributions (Greene, A. 1965; Mays, J. 1974; Novatsky, V. 1975). Such arbitrariness covers the real distribution of external forces and changes in these distributions during the testing process. 
Undoubtedly, an axial stretching or compression of materials is a process having a beginning, duration and end, with varying forces in time. The study of this process on the basis of a static boundary-value problem is doomed to failure in advance. A process with time-varying quantities can not be described by equations in which anything doesn't change with time. This process should be studied on the basis of a new criterion derived from the problem for axisymmetric compression of cylinders and integration of the axial motion's equation.

This study, as shown in (Duishenaliev, T. 2017; Zhakypbekov, A. \& Duishenaliev, T. 2004; Zhakypbekov, A. 1980), proved to be very fruitful. It turns out that the generalized law of Hooke is fundamental. He, as befits a well-grounded physical law, correctly describes the behavior of bodies not only in the field of small deformations, but also at their large levels. The isotropic body is characterized by two constants, which have the same values in the field of both small and large deformations. The new criterion gives a new interpretation to the experimental diagram, which is shown in Fig. 2 (Zhakypbekov, A. \& Duishenaliev, T. 2004).

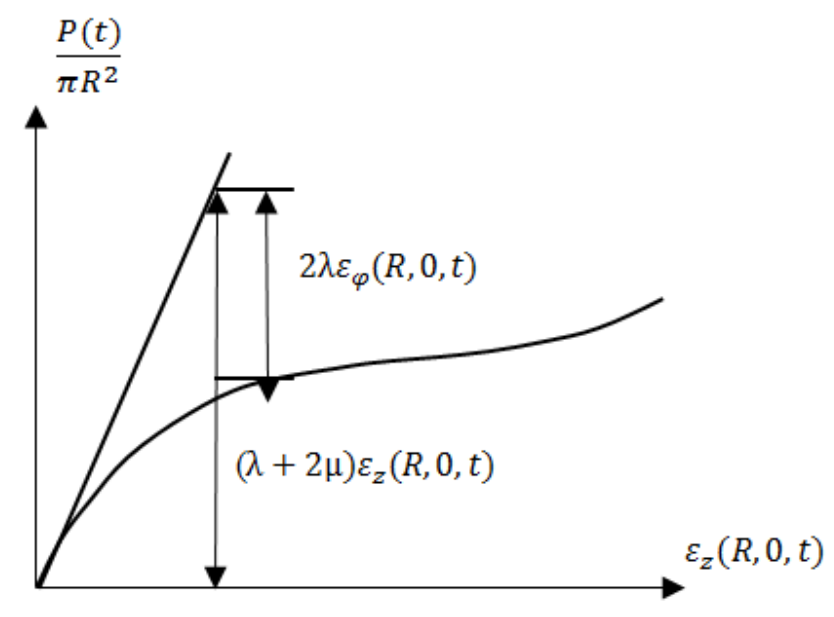

Fig. 2. A new interpretation of the experimental diagram according to A.B. Zhakypbekov.

The new criterion gives its interpretation to other phenomena. Consider them.

\section{Axial compression when fixing an annular deformation}

Suppose that the axial compression is carried out in a way that the values of the annular deformation can be fixed. Such experiments are realized in triaxial compression chambers by adjusting the lateral hydrostatic pressure. If the zero value of the ring strain is fixed $\varepsilon_{\varphi}(R, 0, t)=0$, then the diagram has the form of a direct ray with an angular coefficient $\lambda+2 \mu$ (Fig. 3)

$$
\frac{P(t)}{\pi R^{2}}=(\lambda+2 \mu) \varepsilon_{z}(R, 0, t) .
$$


If any other value is fixed $\varepsilon_{\varphi}(R, 0, t)=c$, The further part of the diagram will have the form of a straight line with the same angular coefficient

$$
\frac{P(t)}{\pi R^{2}}=(\lambda+2 \mu) \varepsilon_{z}(R, 0, t)+2 \lambda c
$$

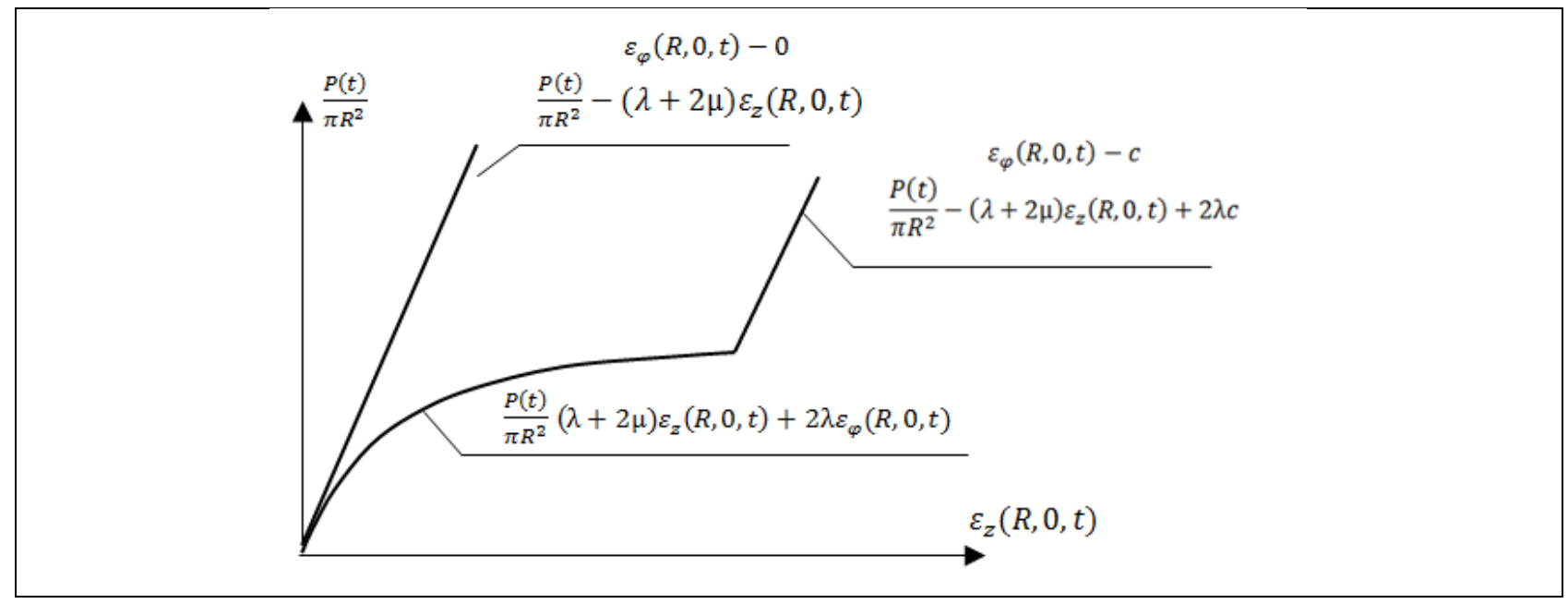

Fig. 3. Straightening the diagrams while fixing the value annular strain

\section{Unloading}

A new criterion

$$
\frac{P(t)}{\pi R^{2}}=(\lambda+2 \mu) \varepsilon_{z}(R, 0, t)+2 \lambda \varepsilon_{\varphi}(R, 0, t)
$$

At the same time, it is also an equation of the load-strain diagram. In it, the law of changing the external load $\mathrm{P}(\mathrm{t})$ is arbitrary, it can be specified as desired. Suppose, from a certain level of deformation, the load is removed quickly and is also applied back as quickly. If the ring strain remains constant, the line of unloading and loading will be a straight line with an angular coefficient $\lambda+2 \mu$. If unloading and loading are not carried out so quickly, this process will be accompanied by a change in the magnitude of the annular deformation. In this case, unloading and loading will proceed along curved lines (Fig. 4).

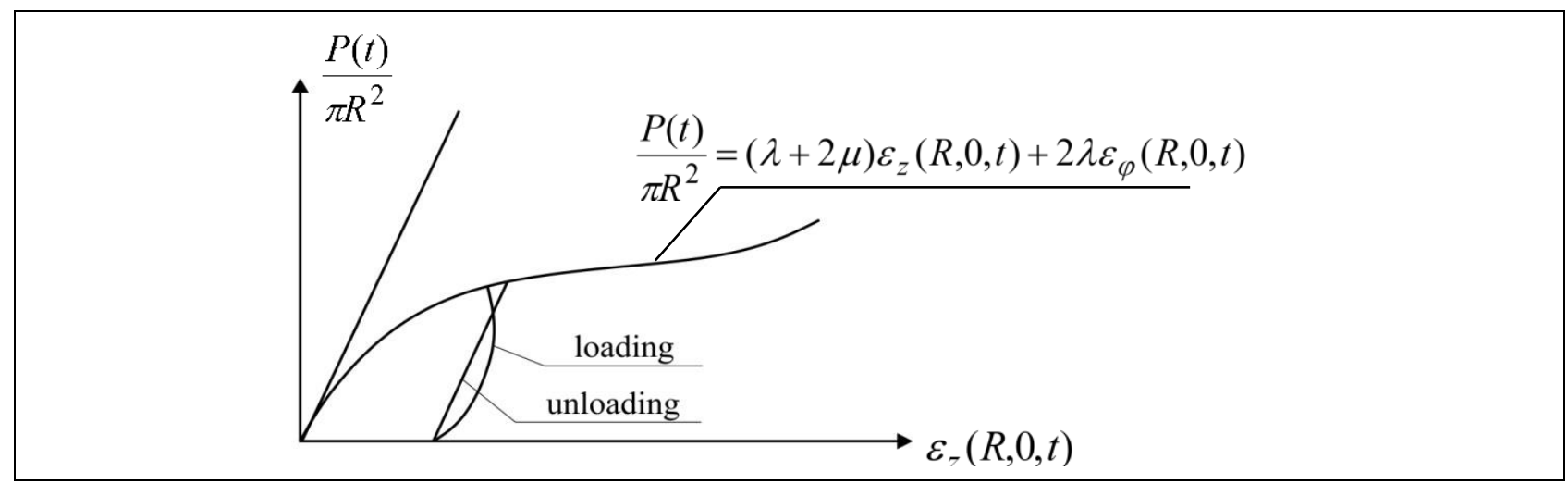

Fig. 4. Unloading and Loading Lines 
At any point in the diagram shown in Fig. 4, the equation (3) must be satisfied. At the end of the unloading $(\mathrm{P}(\mathrm{t})=0)$, the process of changes $\varepsilon_{z}(R, 0, t), \varepsilon_{\varphi}(R, 0, t)$ usually lasts some time (the so-called residual elastic deformations). We denote by $\varepsilon_{z}^{0}, \varepsilon_{\varphi}^{0}$ the values of the axial and annular deformations after the completion of this process.

Equation (3) takes the form

$$
\varepsilon_{z}^{0}=-\frac{2 \lambda}{\lambda+2 \mu} \varepsilon_{\varphi}^{0}
$$

If $\varepsilon_{\varphi}^{0}=0$, then deformations acquired during loading disappear. If $\varepsilon_{\varphi}^{0} \neq 0$, then $\varepsilon_{z}^{0} \neq 0$. Zhukov, A (Zhukov, A. 1954), referring to the experimental data, notes that the residual axial strain is greater than the residual ring strain almost twice. This circumstance is in good agreement with the relation (4) ( $\lambda$ almost an order of magnitude more $\mu$ ).

\section{Creep}

Write a new criterion in the form

$$
\varepsilon_{z}(R, 0, t)=\frac{1}{+2}\left(\frac{\mathrm{P}_{0}}{\mathrm{R}^{2}}-2 \lambda \varepsilon_{\varphi} 2(R, 0, t)\right)
$$

At time $\mathrm{t}=0$, the axial load $P_{0}$ is applied to the sample and then it is maintained constant. It follows from equation (5) that, immediately from the application of the load, the value of the axial strain will be equal to

$$
\varepsilon_{z}(R, 0,0)=\frac{1}{+2} \frac{\mathrm{P}_{0}}{\mathrm{R}^{2}}
$$

Using this equation, write (5) in the form

$$
\varepsilon_{Z}(R, 0, t)=\varepsilon_{z}(R, 0,0)-\frac{2 \lambda}{\lambda+2 \mu} \varepsilon_{\varphi}(R, 0, t)
$$

From this, it is clear that a further increase in the axial strain will be determined by the process of transverse contraction under tension and transverse expansion under compression.

This process is called creep. If the value of $P_{0}$ is small, then the narrowing of the cross section during tension and expansion during compression after a certain time, as follows from the experiments, will cease. The creep curve in this case has a horizontal asymptote (Fig. 7). 


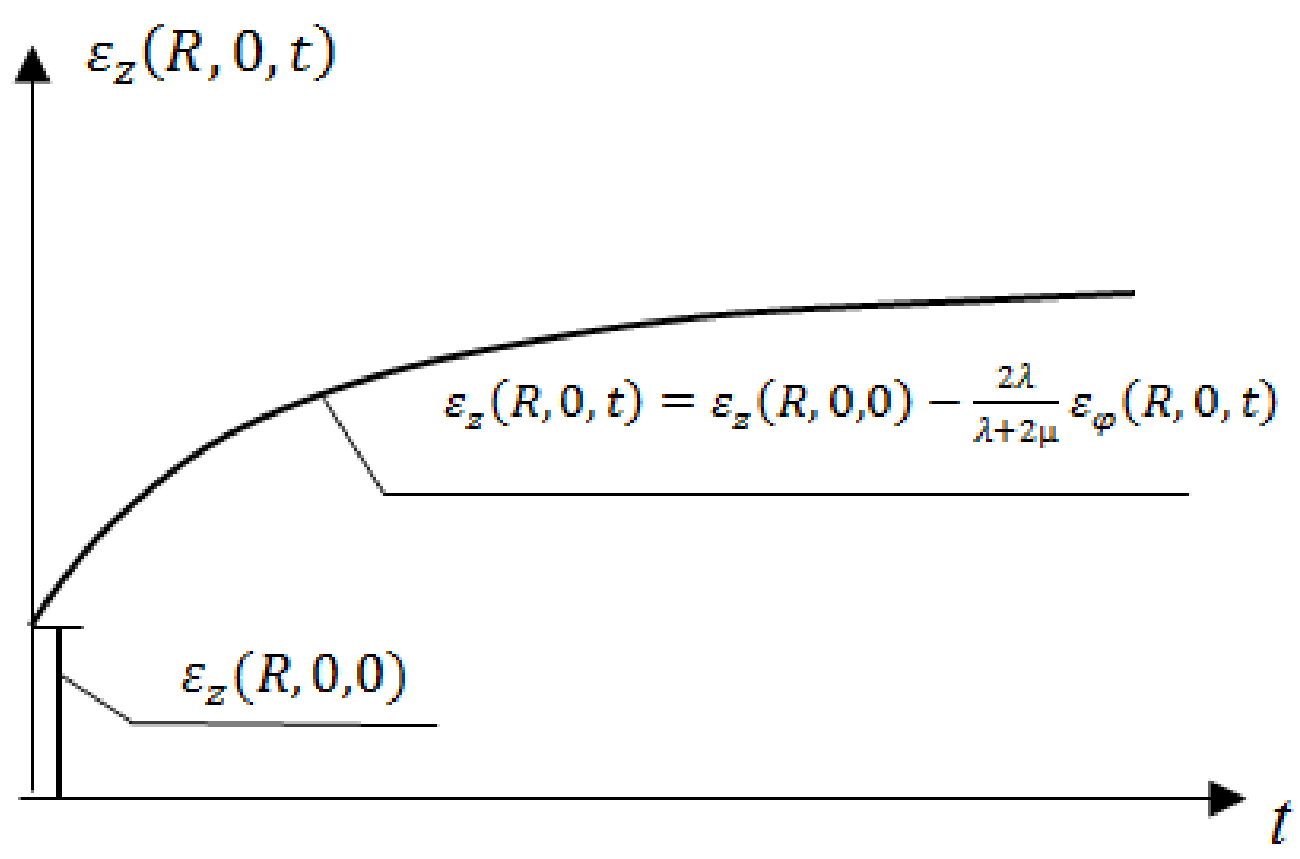

Fig. 5. Creep for small values $P_{0}$.

At large values of $P_{0}$, these processes do not stop. Usually they end with destruction (Fig. 6).

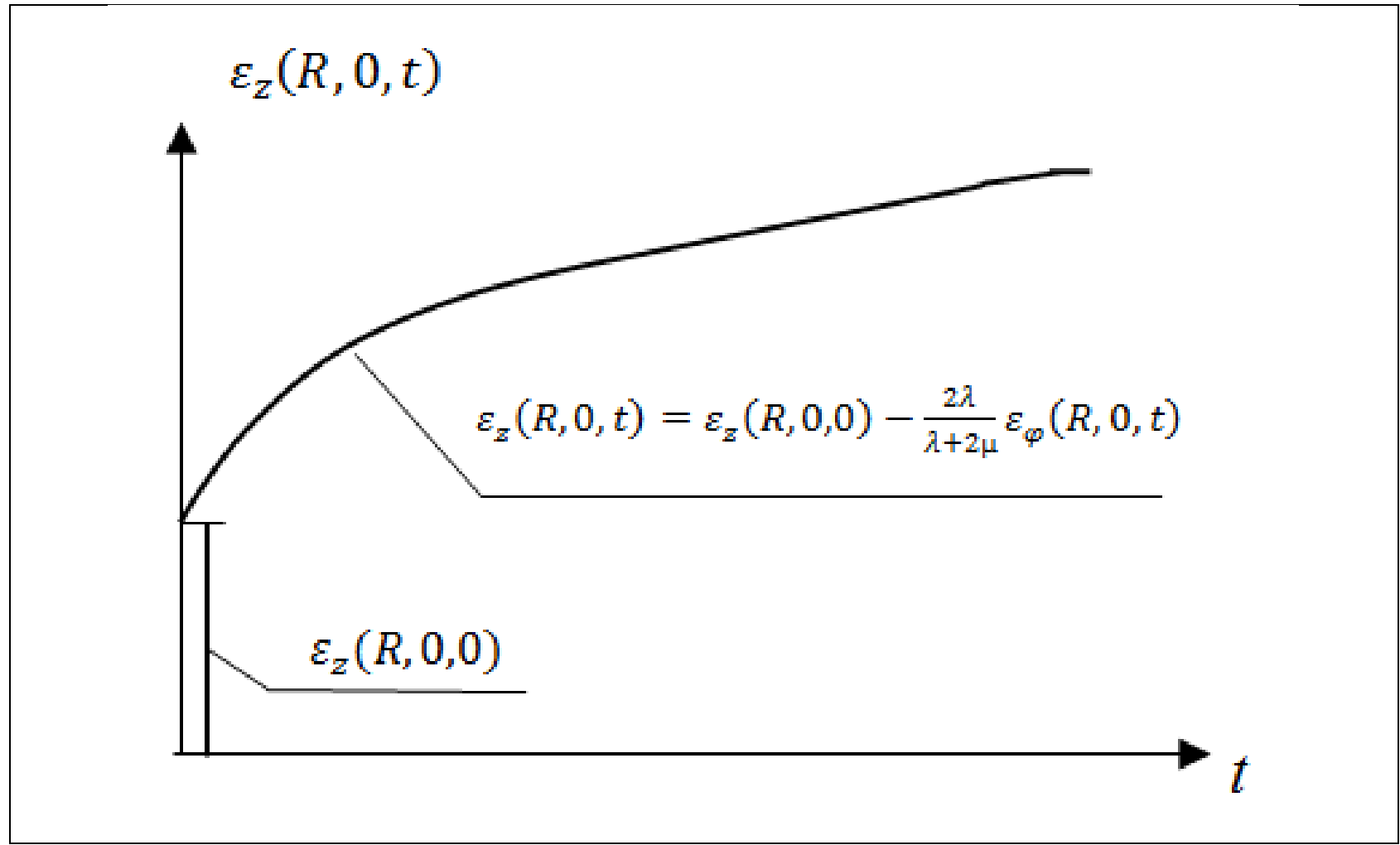

Fig. 6. Creep for large values of $P_{0}$.

The new criterion allows us to consider the phenomenon of creep a little more widely. Generally speaking, fixing the magnitude of the axial load can be produce from any point of the load-strain diagram. Let, as noted in Fig. 7 point $a$ 


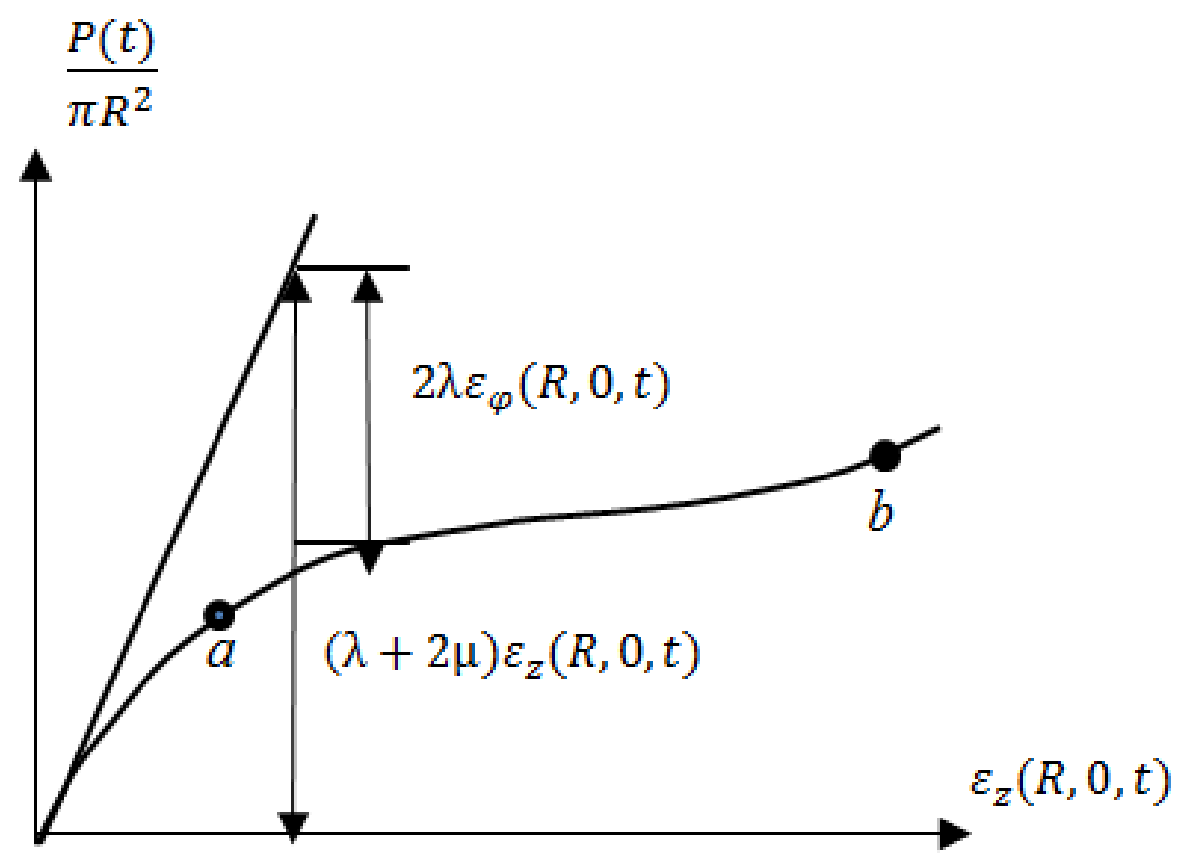

Fig. 7. Diagram load - deformation corresponds the values $\mathrm{t}_{1}, \frac{\mathrm{P}\left(\mathrm{t}_{1}\right)}{\mathrm{R}^{2}}, \varepsilon_{z}\left(R, 0, \mathrm{t}_{1}\right)$, $\varepsilon \varphi\left(R, 0, \mathrm{t}_{1}\right)$, to point $b$-values $\mathrm{t}_{2}, \frac{\mathrm{P}\left(\mathrm{t}_{2}\right)}{\mathrm{R}^{2}}, \varepsilon_{z}\left(R, 0, \mathrm{t}_{2}\right), \varepsilon \varphi\left(R, 0, \mathrm{t}_{2}\right)$. When fixing the value of the load corresponding to point $a$, the creep curve will have the form shown in Fig. 8.

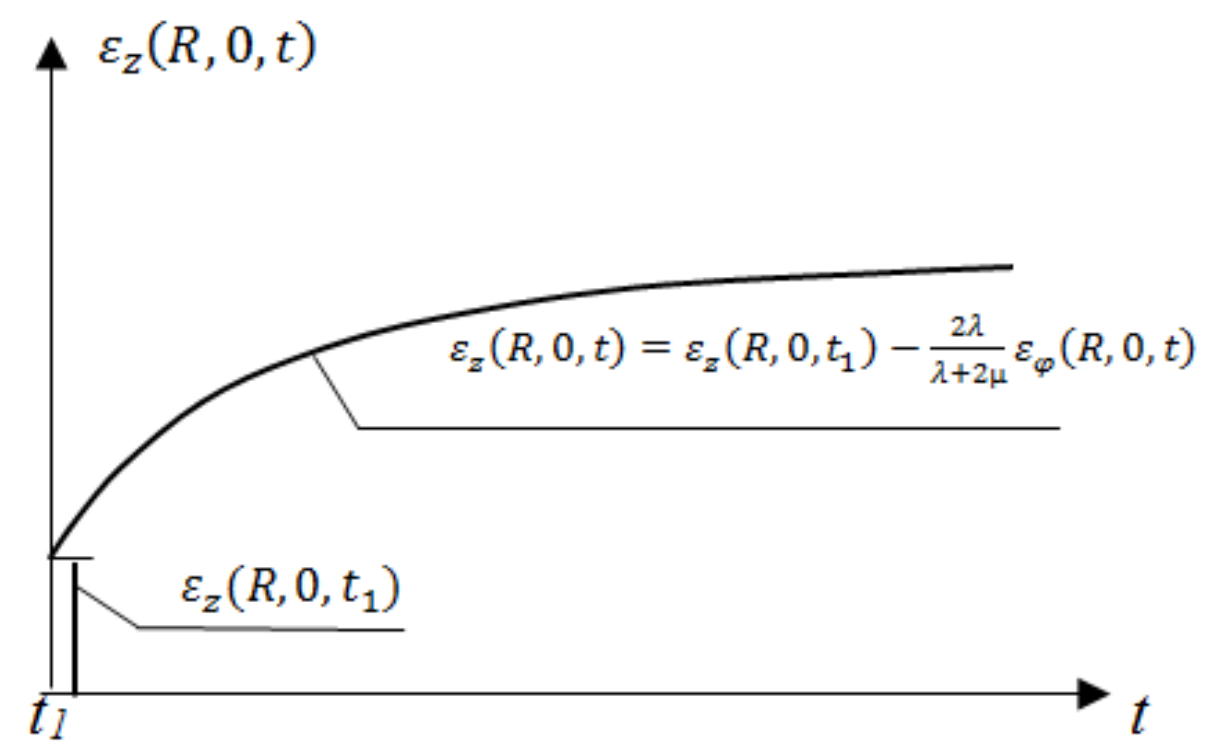

Fig. 8. Creep curve with load value $P\left(t_{1}\right)$

If the value of the axial load corresponding to the point located near the end of the diagram is fixed, then the creep curve will most likely have the form shown in Fig. 9. 


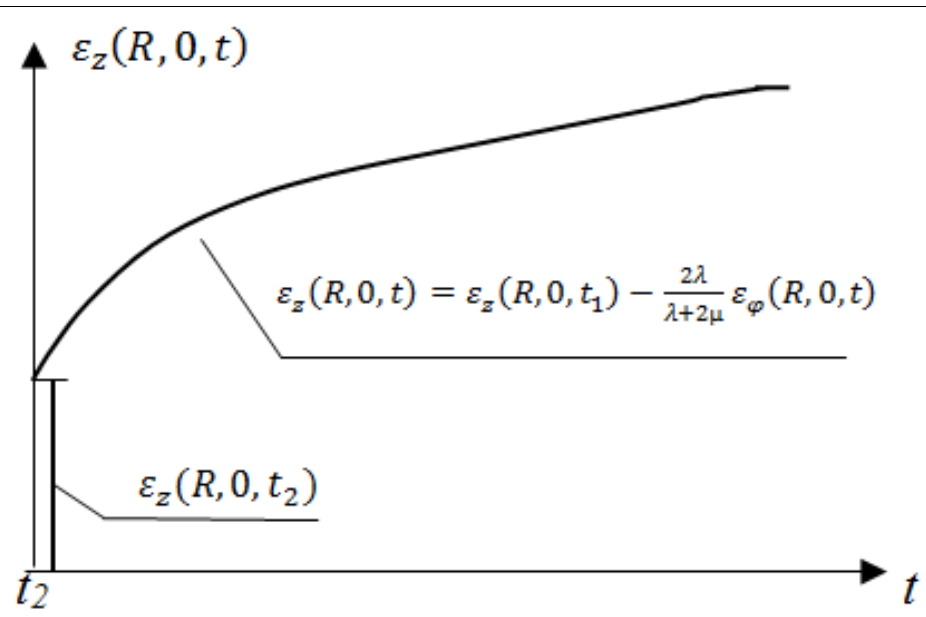

Fig. 9. Creep curve with load value $P\left(t_{2}\right)$

\section{Motionless (Rest or relaxation) of the load}

Above we considered a new criterion (3) from the standpoint of its two variables. Here we consider it from the point of axial deformation. The behavior of the body at a fixed value of the axial strain was called the relaxation of the voltage. This name is associated with the perception of the experimental diagram as a law between deformation and voltage. The new criterion rejects this perception. Here it is more correct to talk about relaxation of the load.

Suppose, at the time $t=0$, the axial load $P_{0}$ is instantly applied to the sample. In this case, a deformation occurs in the direction of the force, which we denote by $c$

$$
c=\varepsilon_{z}(R, 0,0)
$$

and which is further maintained constant. A further change in the magnitude of the load is attributed to the new criterion by the time variation of the value of the annular deformation (Fig. 10).

$$
\frac{P(t)}{\pi R^{2}}=(\lambda+2 \mu) c+2 \lambda \varepsilon_{\varphi}(R, 0, t)
$$

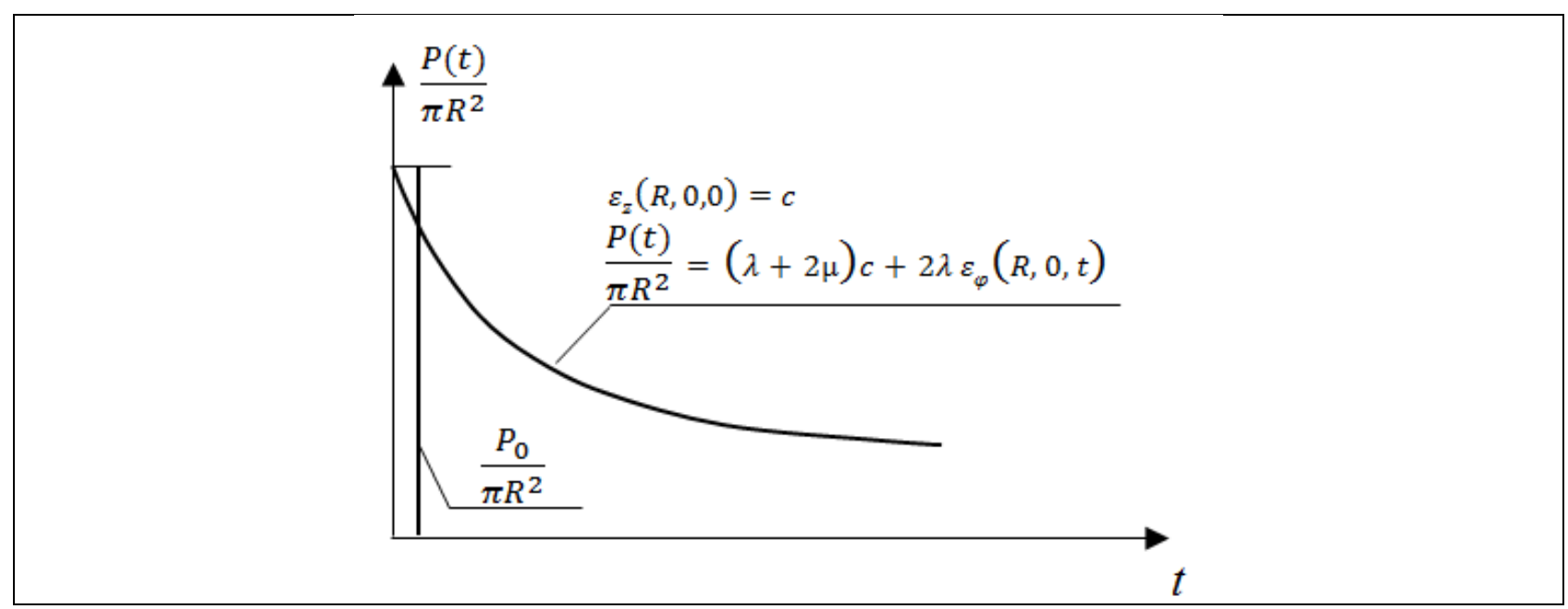

Fig. 10. The relaxation curve when fixing the value of the axial strain 
Duishenaliev, T.; Duishembiev, A. \& Mekenbaev, B.: Criterion for Verification of t...

\section{Conclusion}

The generalized Hooke's law, as shown in (Duishenaliev, T. 2017; Zhakypbekov, A. \& Duishenaliev, T. 2004), well describes the results of experiments in all areas of deformation. When deriving the load-deformation diagram equation the integral form is used of the boundary condition $P(t)=\int_{0}^{R} \int_{0}^{2 \pi} p_{z}(r, t) r d r d \varphi$, which is right for any distributions, as well as the possible evolution of these distributions in the process of deformation. The new criterion, which is also an equation of the loadstrain diagram, can serve as a quantitative expression of arbitrarily repeated unloading and loading, creep and relaxation. This suggests that the generalized Hooke's law in the deformation motion is just as fundamental as the law of Newton in spatial motion. They are consonant: the force is proportional to the measure of spatial motion - acceleration; and the voltages are proportional to the measures of deformation motion-relative deformations.

\section{References}

Demidov, S. (1979). Theory of elasticity, Higher School, Moscow

Duishenaliev, T. (2017). Nonclassical solutions of the mechanics of a deformed, Publishing house MPEI, ISBN: 978-5-7046-1840-9, Moscow

Greene, A. (1965). Large elastic deformations and non-linear continuum mechanics, Mir, Moscow

Ilyushin, A. (1971) Continuum mechanics, Publishing House Moscow University, Moscow

Mays, J. (1974) Theory and Problems of Continuum Mechanics, Mir, Moscow Novatsky, V. (1975) Theory of elasticity, Mir, Moscow

Rudskoy, A. \& Duishenaliev, T. (2016) Strength and plasticity of materials, Publishing House St.Petersburg. polytechnical University, St.Petersburg

Zhakypbekov, A. \& Duishenaliev, T. (2004). Equation of load-strain diagram, Mathematical Journal, Vol. 4.-No.3 (13)., (27-41)

Zhakypbekov, A. (1980). Non-linearity of stress-strain diagrams as a consequence of Hooke's law, Proceedings of the Conference on the Destruction of Rocks. Sat. articles, Ilim, Frunze

Zhukov, A. (1954) - On the Poisson's Ratio in the Plastic Domain, Journal News of the USSR Academy of Sciences, Otd.1954, No. 12., (86-91) 